\title{
城市污水处理项目 PPP 模式的应用与风险探究
}

\section{The Application of PPP Model in Urban Sewage Treatment Project and Its Risk Exploration}

于印鹏

Yinpeng $\mathrm{Yu}$

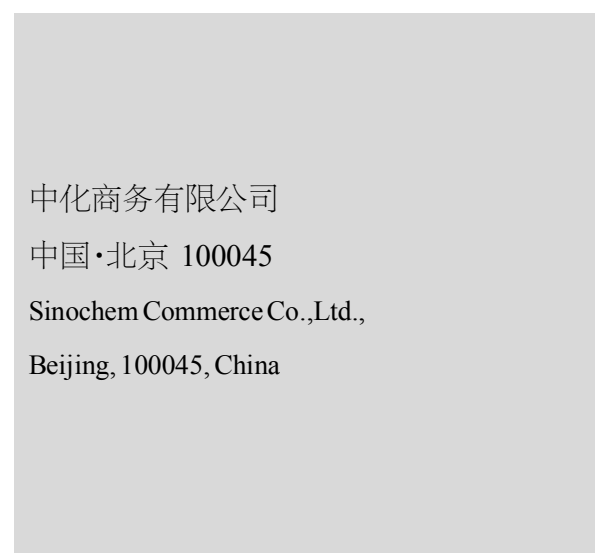

【摘 要】PPP 模式是一种新的融投资模式,它具有风险低、效率高的特点,因此,已经被应 用在城市污水处理过程中。基于此,论文主要将阐述城市污水处理项目 PPP 模式的应用与 存在的风险。

【Abstract】PPP mode is a new financing and investment mode, which has the characteristics of low risk and high efficiency. Therefore, it has been applied in the process of urban sewage treatment. Based on this, this paper mainly expounds the application and existing risks of PPP mode in urban sewage treatment projects.

【关键词】城市污水处理项目; PPP 模式; 应用; 风险

【Keywords 】urban sewage treatment project; PPP model; application; risk 【DOI】10.36012/etr.v1i2.235

\section{1 引言}

随着中国社会经济的持续快速发展，各行各业对于资源 的需求量也在持续增多，从而使得中国的环境问题越来越严 重, 其中污水处理问题是非常主要的问题之一。而 PPP 模式 是一种新型的融投资模式, 它可以和市场经济进行有效联系, 将这种模式应用在城市污水处理项目中, 可以更加高效地处 理污水, 并有效解决中国的环境问题。

\section{2 城市污水处理项目 PPP 模式的应用}

\section{1 融资模式}

在城市污水处理项目中, 可以采用资产证券化的融资模 式, 通过选择一组流动性相对较差的资产, 而且这组资产在一 个阶段内拥有较为稳定的现金流，如未来一段时期的污水处 理收益权，以在金融市场中流通且信用较高的债券资产替代 中介机构的信用增级。使用这种模式能够将社会中存在的闲 散资金吸引到污水处理项目中，并且也能够缓解政府与社会 的出资压力。

例如, 中国证监会在 2006 年批准了“南京城建污水处理 收费资产支持收益专项资产管理计划”, 这一计划将南京城建 在之后 4 年内所得的污水处理收费收益权当作基础资产, 发
行规模为 7.21 亿元的专项计划收益凭证,分 4 期发行,预期 收益率是 $2.9 \%$ 到 $3.9 \%$ 不等。采用资产剥离、信用增级等模 式, 大大降低了证券发行风险以及经营风险, 从而也就给中国 江苏南京市的污水处理领域开创了新的融资途径，并给同类 项目积累了经验。

\section{2 合作模式}

因为各地政府平台公司拥有丰厚的水务资产，而且这类 非业主资产较多,负担重,仅仅由政府部门负责运营难度相对 较大, 效率也相对较低。所以, 政府部门或者是相关的平台公 司可以把这部分水务资产与应付财政的专项负债列出来展开 评估,将水务资产的净资产用于投资, 并将社会资本用现金出 资, 以此来建立一个项目公司 ${ }^{[1]}$ 。具体的公私合作创新模式如 图 1 所示。

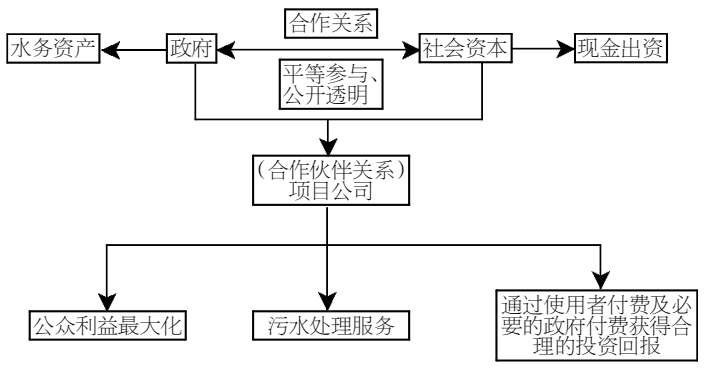

图 1 公私合作创新模式 
市政工程 Municipal Engineering

在这种模式中, 中国国资委仍旧是水务资产的产权主 体, 项目公司拥有资产所有权,在政府部门把特许经营赋予 项目公司的时候, 也就把项目建设权与特许经营管理权转让 给社会投资者, 在项目特许经营期完成以后, 项目公司需要 无偿地将项目转让到政府部门或者是获得政府部门授权的 相关机构。

但是, 这种模式也存在一些缺点: (1)水务资产的评估较为 复杂。对于水务资产的评估范围较大, 必须要使用专业的评估 机构, 最终的评估结果不但应该由发改委/局批准, 也要得到 债权人的认同。2政府部门的一次性获得资金减少。政府部门 进行股权转让定价的参考标准是公司的所有者权益，因为负 债的增多，使得一部分股权转让的一次性获得资金少于一定 年限的经营权或收费权转让所得资金。

\section{PPP 模式在污水处理项目上的风险}

\section{1 自然环境风险}

所谓自然环境风险,指的就是地质灾害、气候环境恶化等 人们不能避免的灾难。政府与社会资本既无法预测这种灾害, 也不能对其进行有效控制, 然后就会对项目造成严重的负面 影响 ${ }^{[2]}$ 。例如, 中国北京市某水厂工程, 预期每天的供水能力 是 $4.5 \times 10^{5} \mathrm{t}$, 水源由密云水库提供, 但因中国北京的天气比较 干早，从 20 世纪后期开始，密云水库的水位不断降低, 到 1999 年基本枯竭, 2004 年，政府和社会资本联合成立的安菱 联合体因为水源问题不能解决而向中国北京市提交了中止项 目的申请,并要求赔偿违约金。

\section{2 政府风险}

出现政府风险的主要原因是中国在 PPP 应用方面积 累的经验相对较少,一些地方政府部门难以按照市场发展 情况有效地处理污水问题。虽然目前中国已经颁布了多个 将 PPP 模式当作运行主体的法律政策, 但是,这些政策并 不够完善, 难以使用到具体的项目中。在这种情况下, 在使 用 PPP 模式解决问题的时候, 总是需要耗费大量的时间与 金钱。

例如, 2000 年, 中国吉林长春市政府出台了《长春汇津污 水处理专营管理办法》,排水公司和中国长春汇津公司的合作 得到了中国吉林长春市某污水处理长的经营权，该项目由自 来水公司负责对用户收取污水处理费用，并通过排水公司上 交给汇津公司。从 2002 年开始, 中国吉林长春市排水公司故 意拖欠污水处理费用,到 2003 年 3 月, 中国吉林长春市政府 决定废除这一项目。从 2003 年 4 月开始,排水公司支付污水
处理费的工作全面停止。在这一个项目中, 因为投资回报率太 高，使得换届以后的政府部门不愿意根据合同规定继续按时 支付污水处理服务费用, 合同难以兄现, 所以, 中国吉林长春 市政府通过政策途径单方面的取消了合同。

\section{3 融资风险}

所谓融资风险, 其中涉及的内容有: 融资计划的可行性、 融资成本的合理性等, 具体的表现形式是资金筹集与还款困 难。因为政府部门在确定社会资本的过程中,也会针对融资 计划展开谈判与评估, 只有融资计划得到政府的许可, 项目 才会正式启动。因为 PPP 项目的谈判时间相对较长, 中标以 后才会针对合同内容进行探讨, 这与签约时间存在一定的过 渡期。在这段时间内, 融资计划会被市场利率的变化影响, 从 而就可能会导致最开始制定的计划难以落实, 因此, 项目融 资风险的具体表现是谈判时间太长使得影响融资计划的因 素产生变化。

此外, 在 PPP 项目建设过程中, 因为地质、气候等没有纳 入考虑范围的客观影响因素, 使得资金需求量提高, 因此, 项 目建设过程中的融资风险主要指的就是融资资金的增多。

最后, 在 PPP 项目运营的过程中, 也会存在现金流不稳 定、还款困难等融资风险。例如, 在使用债务性融资模式的过 程中, 选择长期银行贷款的作为具体的融资方式, 污水处理厂 用 2 年的时间完成建设并过渡到商业运营阶段，开始有水费 收人。但是, 政府并非以月为单位给运营公司支付污水处理费 用, 而是一个月、一个季度抑或是一年累积支付一次, 运营阶 段的现金流并不够稳定，污水处理厂所承担的还款压力也会 持续加重, 在这种情况下, 项目公司需要承担支付风险, 而银 行需要承担回款风险。

\section{4 结语}

总之, 在社会不断发展的过程中, 环境问题也在不断恶 化, 在这个大背景下, 社会各界对于污水处理行业的重视度持 续提高。但是, 从目前来看, 中国的 PPP 模式还并没有完全成 熟, 因此, 相关部门与工作人员应该加大对于这一模式的研究 与应用力度, 以此来为污水处理领域开拓更加广阔的发展渠 道, 从而也就提高了城市污水处理项目的效率。

\section{参考文献}

[1]蒋兰英.污水处理设施建设 PPP 模式下的融资风险管理探究 [J].财会学习,2018,191(17):213-214.

[2]周思娇.PPP 模式下污水处理服务价格调整模型与政策研究基于最高上限价格管制理论[J].现代经济信息,2018(23):45-47. 